\title{
The Coupling of Phosphate Accumulation to Acid Production by a Non-growing Streptococcus
}

\author{
J. M. TANZER, M. I. KRICHEVSKY AND P. H. KEYES \\ Physiology Section and Laboratory of Histology and Pathology, National \\ Institute of Dental Research, National Institutes of Health, Bethesda, \\ Maryland 20014, and Department of Physiology and Biophysics, Schools of \\ Medicine and Dentistry, Georgetown University, Washington, D.C. 20007
}

(Accepted for publication 28 October 1968)

\begin{abstract}
SUMMARY
Accumulation of phosphate by washed, stored suspensions of stationary phase streptococcal strain SL-I is strictly energy-dependent, essentially unidirectional and coupled stoichiometrically to acid production. At saturating concentrations of extracellular glucose and phosphate, incubation at varying $\mathrm{pH}$ values alters the rates of phosphate accumulation and concomitant fermentation of glucose such that coupling remains intact. Extracellular $\mathrm{pH}$, while not affecting the coupling of phosphate accumulation to acid production, determines the total capacity for accumulation of phosphate and consequently the point of uncoupling of these processes. The conditions of cell storage profoundly affect the $\mathrm{pH}$ dependency of phosphate accummulation. During phosphate accumulation, the intracellular $o-\mathrm{PO}_{4}$ pool contracts by more than $50 \%$. About half of the accumulated phosphate appears in a high molecular weight fraction (i.e. insoluble in cold $\mathrm{HClO}_{4}$ ) under conditions which contraindicate net nucleic acid synthesis, protein synthesis or the incorporation of exogenous glucose carbon into high molecular weight cell constituents. The data are consistent with the hypothesis that stationary phase streptococcus SL-I synthesizes inorganic polyphosphates.
\end{abstract}

\section{INTRODUCTION}

A microaerophilic extracellular dextran-producing streptococcus strain SL-I has been isolated from the mouth of a human and is typical of the HS strains of Fitzgerald \& Keyes (I960), which characteristically form heavy bacterial masses adhering to the surface of teeth. They are associated with"tooth decay in hamsters.

Organisms of this type may rapidly accumulate phosphate from their environment (Luoma, I964). The present study describes a stoichiometric coupling of phosphate accumulation to acid production by SL-I. It also presents presumptive evidence that much of the accumulated phosphate is inorganic polyphosphate.

\section{METHODS}

Preparation of suspensions. Strain SL-I was maintained by passage at IO- to I4-day intervals in NIH fluid thioglycollate medium (Baltimore Biological Laboratories, Baltimore, Md., U.S.A.) containing excess $\mathrm{CaCO}_{3}$. For experiments, $5 \mathrm{ml}$. of a I-dayold culture was inoculated into $500 \mathrm{ml}$. of broth (Jordan, Fitzgerald \& Bowler, 1960) containing $0.5 \%(\mathrm{w} / \mathrm{v})$ glucose and agitated at $37^{\circ}$ in I 1 . flasks until the stationary 
phase was reached. Cocci were harvested by centrifugation at room temperature and washed 3 times with $50 \mathrm{~mm}-\mathrm{KCl}$ containing I mM-potassium phosphate (pH 6.8). Deviations from this procedure are noted in specific experiments. Wash solution was added to the suspensions so that there were $5-6 \mathrm{mg}$. cocci $/ \mathrm{ml}$.

Incubation procedure. To study phosphate accumulation and acid production, $50 \mathrm{ml}$. of stored suspension was stirred rapidly at $37^{\circ}$ in a titration assembly $\mathrm{TTA}_{3}$, titrator, $\mathrm{TTT}_{1}$, and autoburette $\mathrm{ABU}_{1 \mathrm{a}}$ (Radiometer, Copenhagen, Denmark). A constant $\mathrm{pH}$ was maintained with $\mathrm{N}-\mathrm{NaOH}$ and the addition of this titrant was recorded by a Model SRL strip-chart recorder (E. H. Sargent and Co., Chicago, Ill., U.S.A.). After Io min. temperature equilibration, $2 \cdot 25 \mu \mathrm{C}$. $\mathrm{Na}_{2} \mathrm{H}^{32} \mathrm{PO}_{4}$ (New England Nuclear Corp., Boston, Mass., U.S.A.) were added. The specific activity of the final incubation medium was usually $45 \mathrm{~m} \mu \mathrm{C}$. $/ \mu$ mole; isotope solution was always less than $0.35 \%$ of the incubation mixture. Unless exogenous glucose was added, cellular levels of radioactivity remained constant from 30 sec. after the addition of isotope to over $2 \mathrm{hr}$. Ten to $15 \mathrm{~min}$. after the addition of isotope, glucose was added to a final concentration of $0.20 \%(\mathrm{w} / \mathrm{v})$, unless otherwise indicated, which diluted the suspension by $\mathrm{I} \%$. The greatest dilution of the incubation mixture resulting from the addition of titrant was $2.4 \%$. Five ml. samples of suspension were filtered at timed intervals through $47 \mathrm{~mm}$., $0.45 \mu$ pore diameter Millipore discs (Millipore Filter Corp., Bedford, Mass., U.S.A.). Sampling and filtration required approximately $30 \mathrm{sec}$.

Throughout these experiments the $\mathrm{pH}$ stat incubation flask was open to the air. Incubation mixtures left open to the air, sparged with air, or sparged with argon gave identical values for both phosphate accumulation and acid production.

Acid production was calculated from the recorded addition of titrant to the suspension and from the normality of the titrant.

Phosphate accumulation. Filter discs and samples of filtrate were placed directly into scintillation fluid containing $4 \%$ (w/v) Cab-O-Sil (Cabot Corp., N.Y., N.Y., U.S.A.) (Kinard, 1957; Gordan \& Wolfe, 1960). The discs dissolved and the cocci distributed evenly in the gel, no disc-associated quenching occurred. ${ }^{32} \mathrm{P}$ radioactivity evaluations were carried out with a Tri-Carb liquid scintillation spectrometer, series 3 I 4 E (Packard Instrument Co., LaGrange, Ill., U.S.A.).

For cold $\mathrm{HClO}_{4}$ extracts of cocci, samples of suspension were filtered through Millipore discs. These were placed into ice cold $0 \cdot 3 \mathrm{~N}-\mathrm{HClO}_{4}$ and extracted for Io min. with intermittent shaking. This material was filtered again and one volume of filtrate was added immediately to one half volume of $0.8 \mathrm{M}$-sodium acetate. Orthophosphate (o- $\mathrm{PO}_{4}$ ) was analyzed by the Burnham \& Hageage (1967) modification of the method of Potter (1947). Perchloric acid treatment and analysis of samples of sodium pyrophosphate, sodium trimetaphosphate, sodium tripolyphosphate, sodium hexametaphosphate (all obtained from The Monsanto Co., St Louis, Mo., U.S.A.) and trisodium adenosine triphosphate (Sigma Chemical Co., St Louis, Mo., U.S.A.) yielded less than I $\%$ of the absorbance of an equivalent concentration of $o-\mathrm{PO}_{4}$.

Total phosphate analysis was carried out after digestion of Millipore discs and trapped cocci in $10 \mathrm{~N}_{-} \mathrm{H}_{2} \mathrm{SO}_{4}$ at $150^{\circ}$ for $\mathrm{I} \mathrm{hr}$ followed by removal of carbon by treatment with $\mathrm{H}_{2} \mathrm{O}_{2}$ (Umbreit, Burris \& Stauffer, 1957). Then $\mathrm{H}_{2} \mathrm{O}_{2}$ was destroyed by adding water and boiling. Samples of the digest were analysed for radioactivity. Neither increased quenching nor loss of radioactivity resulted from this procedure.

Radiochemical purity of ${ }^{32} \mathrm{P}$ was evaluated by column chromatography on Dowex-I- 
bicarbonate- $8 x$ according to the method of Martonosi (1960). Only one radioactive peak was obtained and this peak accounted for $99.6 \%$ of the label eluted from the column. Concentrations of $\mathrm{KHCO}_{3}$ sufficient to regenerate the column did not elute further radioactivity.

Measurement of trapped medium and cell weight. The volume of medium trapped in the Millipore disc was determined by filtering $\mathrm{KCl}$-phosphate wash solution through the disc, weighing the disc, and subtracting the weight of a dry disc. The weight of the cocci in a $5 \mathrm{ml}$. sample of suspension was determined by filtering this sample, weighing the disc, and subtracting the weight of a wet disc. These procedures were carried out with each experiment. The maximum error in cell weight evaluation due to neglecting the displacement of medium by cocci is $6 \%$. In calculating the amount of phosphate in cocci, appropriate correction was made for the phosphate contained in the trapped medium.

Evaluation of growth. Growth, as indexed by increased DNA, was examined during incubation. Five ml. samples of suspension were added to an equal volume of $\mathrm{I} \cdot \mathrm{O} \mathrm{N}-$ $\mathrm{HClO}_{4}$ at $70^{\circ}$ and extracted for $20 \mathrm{~min}$. according to the method of Ogur \& Rosen (1950). The extract was analysed for DNA by the method of Burton (1956) employing 2deoxy-D-ribose standards (Sigma Chemical Co., St Louis, Mo., U.S.A.). Colorimetric chemical analysis was carried out with a Model 300 micro-sample spectrophotometer (Gilford Instrument Laboratories, Inc., Oberlin, Ohio, U.S.A.). No increase of DNA was observed.

\section{RESULTS}

Stoichiometry of phosphate accumulation and acid production with varying initial extracellular glucose concentrations. The initial rate of phosphate accumulation ( $285 \mu$ moles/g. cocci/hr) was independent of the initial extracellular glucose concentration in the range studied (Fig. I $a$ ). By contrast, the total amount of phosphate taken up was a function of the glucose concentration. In the absence of exogenous glucose, no phosphate uptake was detectable.

In the same experiment, the initial rate of acid production was independent of the initial concentration of glucose in the medium and proceded at approximately 5.2 m-equivalents/g. cocci/hr. (Fig. $\mathrm{r} b$ ). Thus, the rate limiting step in glucose catabolism appeared to be saturated. In the absence of exogenous glucose, acid production from endogenous metabolic stores was very slow.

The stoichiometric relationship between phosphate accumulated at any given time and acid produced at that same time is shown in Fig. I $c$. The relationship delineated was independent of the initial exogenous glucose concentration. The $\mu$ mole of phosphate accumulated per m-equivalent of acid produced continuously decreased and approached a limit.

Stoichiometry of phosphate accumulation and acid production with varying initial extracellular phosphate concentrations. As shown in Fig. $2 a$, the initial rate of phosphate accumulation became independent of the initial environmental phosphate level at concentrations of I $\mathrm{mM}$ or greater. This maximal rate was approximately $520 \mu \mathrm{mole} / \mathrm{g}$. $\operatorname{cocci} / \mathrm{hr}$.

The corresponding initial rate of acid production, at phosphate concentrations of I mM or greater, was about $5 \cdot 1 \mathrm{~m}$-equiv./g. cocci/hr and there was no initial lag (Fig. $2 b$ ). At lower initial phosphate concentrations acid production rates were slower and a lag was observed with $0.2 \mathrm{~mm}$ and 'no' phosphate. 
Again, phosphate accumulation and acid production were stoichiometrically related in a progressively decreasing manner (Fig. $2 c$ ). At the lower phosphate concentrations ( $<$ I $\mathrm{mM}$ ) the ratio of phosphate accumulation to acid production was decreased. Presumably this was due to the lack of saturation of the phosphate accumulation system.

Stoichiometry of phosphate accumulation and acid production wtih varying extracellular pH. A stoichiometric relationship between processes, each occurring at maximal rates, does not necessarily imply coupling of those processes. In order to demonstrate that

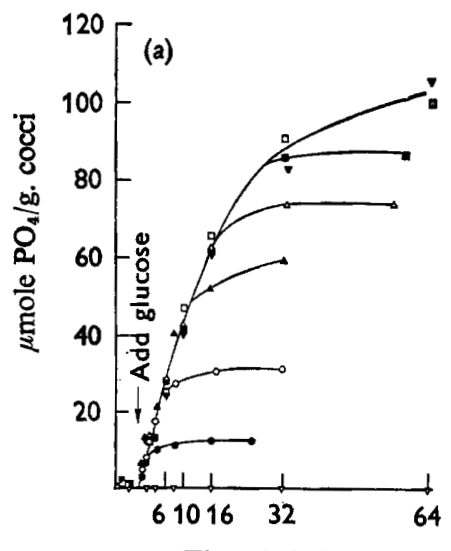

Time (min.)
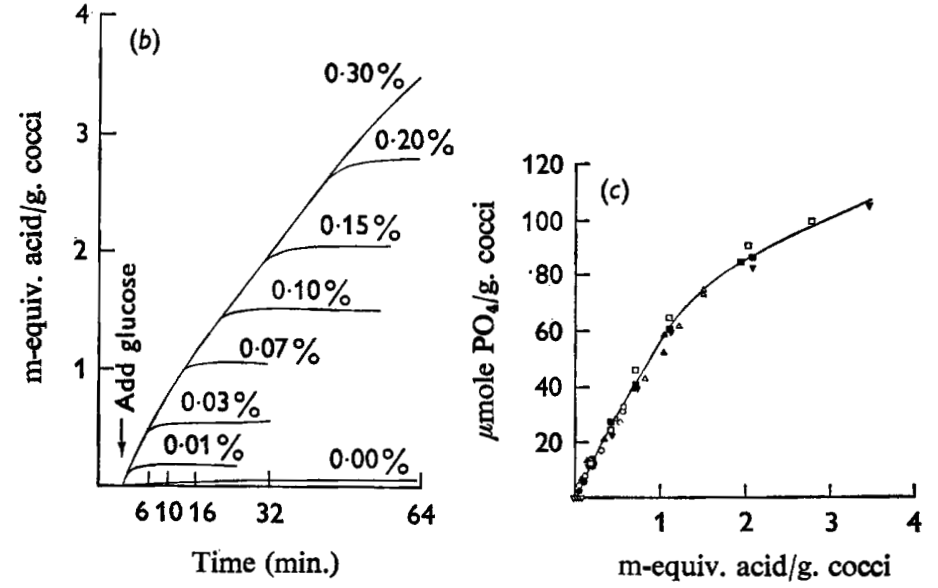

Fig. I. Relationship of phosphate accumulation $(a)$, acid production $(b)$ and the stoichiometric relationship of phosphate accumulation and acid production $(c)$ to the initial glucose concentration of the incubation medium. Glucose was added to a concentration of $0.00 \%(\nabla)$, $0.01 \%(0), 0.03 \%(0), 0.07 \%(\Delta), 0.10 \%(\Delta), 0.15 \%(\square), 0.20 \%(\square)$ or $0.30 \%(\nabla)$ after the addition of $2 \cdot 25 \mu \mathrm{C} \mathrm{Na}{ }_{2} \mathrm{H}^{32} \mathrm{PO}_{4}$.
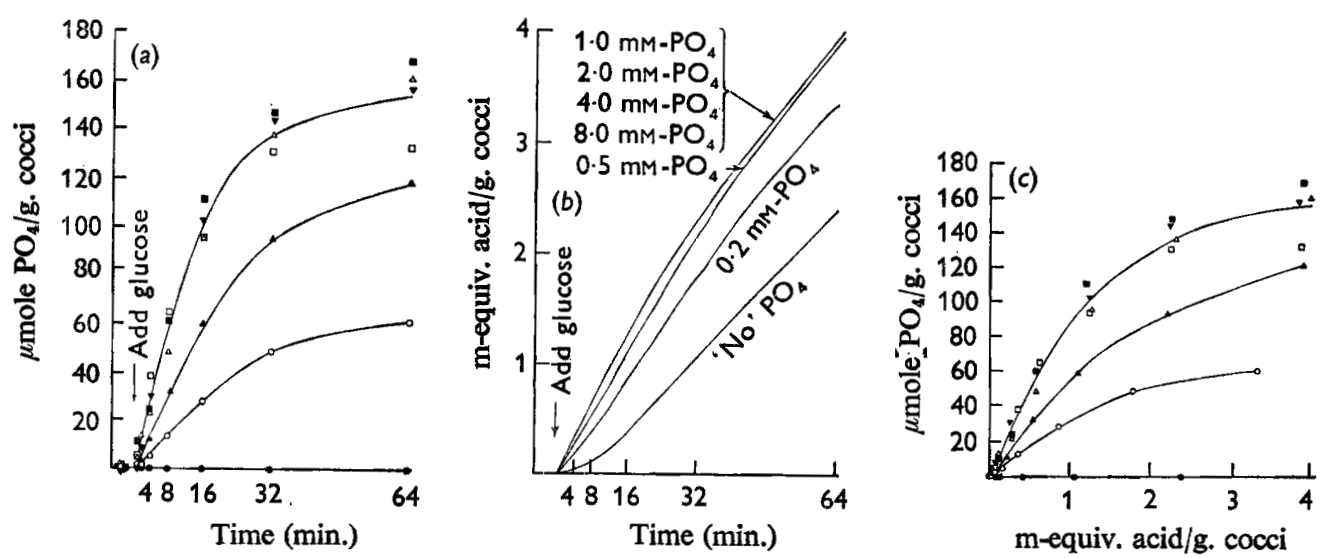

Fig. 2. Relationship of phosphate accumulation (a), acid production $(b)$ and the stoichiometric relationship of phosphate accumulation and acid production $(c)$ to various initial phosphate concentrations of the incubation medium. Cocci were incubated in $50 \mathrm{mM}-\mathrm{KCl}$ containing the following con/entrations of phosphate (mM): 'No' phosphate (0), $0.2(\mathrm{O})$, $0.5(\Delta), \mathrm{I} \cdot \mathrm{O}(\triangle), 2 \cdot 0(\square), 4.0(\square), 8.0(\nabla)$. Glucose was added to the incubation medium to $0.20 \%$ after the addition of $2 \cdot 25 \mu \mathrm{C} \mathrm{Na} \mathrm{H}^{32} \mathrm{PO}_{4}$. 
the rate of phosphate accumulation and the rate of acid production are actually coupled, incubations were carried out with saturating levels of environmental phosphate and glucose, but with varying environmental $\mathrm{pH}$, so that the rates of processes would be changed. The $\mathrm{pH}$ range $7 \cdot 2$ to $4 \cdot 6$ was chosen for study since this is the approximate range existing in the natural environment from which these cells were isolated (Dr G. Charlton, personal communication).

Experiments were carried out in two ways. In the first, the cocci were washed and stored in I mM-phosphate at the $\mathrm{pH}$ values at which they were subsequently incubated. In the second, the cocci were washed and stored in I mM-phosphate at $\mathrm{pH} 6.8$ and adjusted to the required $\mathrm{pH}$ with $\mathrm{N}-\mathrm{NaOH}$ or $\mathrm{HCl}$ immediately before testing.

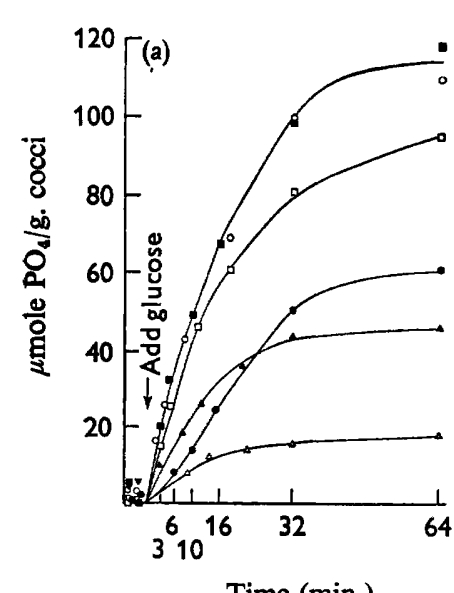

Time (min.)

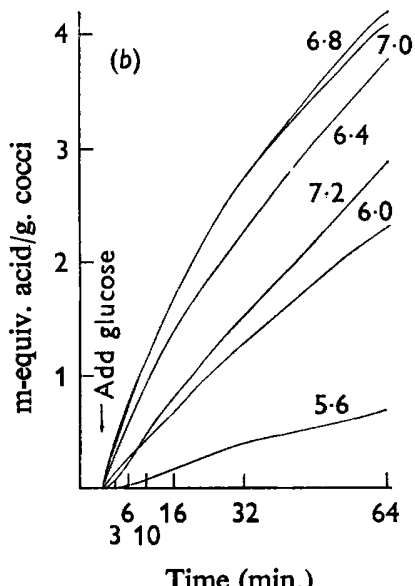

Time (min.)

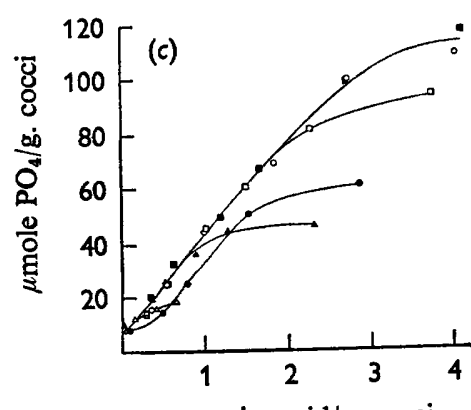

m-equiv. acid/g. cocci

Fig. 3. Relationship of phosphate accumulation (a), acid production (b) and the stoichiometric relationship of phosphate accumulation and acid production $(c)$ to the $\mathrm{pH}$ of the wash, storage and incubation medium. Cocci were washed, stored and incubated in $50 \mathrm{~mm}$ $\mathrm{KCl}+\mathrm{I} \mathrm{mM}$ phosphate medium at the following pH values: $7 \cdot 2(\bullet), 7 \cdot 0(0), 6 \cdot 8(\square), 6 \cdot 4(\square)$, $6.0(\triangle)$ or $5.6(\triangle)$. Glucose was added to the incubation medium to $0.20 \%$ after the addition of $2.25 \mu \mathrm{C} \mathrm{Na} \mathrm{H}^{32} \mathrm{PO}_{4}$.

With cocci stored at the same $\mathrm{pH}$ level as the experimental incubations, the highest initial velocity of phosphate accumulation $(430 \mu \mathrm{mole} / \mathrm{g}$. cocci $/ \mathrm{hr})$ and the highest accumulative capacity were observed at $\mathrm{pH} 6 \cdot 8$ and $7 \cdot 0$ (Fig. $3 a$ ). The accumulation rates and capacities at $\mathrm{pH} 6.4,6.0$ and 5.6 were progressively lower. The rate and capacity at $\mathrm{pH} 7 \cdot 2$, after an initially slower accumulation, was intermediate between those at 6.4 and 6.0. Previous experiments had shown no phosphate uptake at $\mathrm{pH} 5^{\circ} 0$. Thus there appeared to be a functional relationship between the rate and the capacity of phosphate accumulation under these conditions of storage and incubation.

Similarly, acid production rates (Fig. $3 b$ ) showed the same relative behaviour as phosphate accumulation rates: 6.8 and $7 \cdot 0>6.4>7.2>6.0>5.6$. The initial rates ranged from about $7.9 \mathrm{~m}$-equiv./g. cocci/hr at $\mathrm{pH} 6.8$ and 7.0 to $0.64 \mathrm{~m}$-equiv./g. cocci/hr at $\mathrm{pH} 5 \cdot 6$. There was an initial delay in acid production at $\mathrm{pH} \mathbf{7 \cdot 2}$.

The stoichiometric relationship of phosphate accumulation and acid production was essentially the same at $\mathrm{pH} 7 \cdot 0,6 \cdot 8,6 \cdot 4,6 \cdot 0$ and $5 \cdot 6$ (Fig. $3 c$ c). At pH 7.2, the same relationship developed after a brief period of acid production unaccompanied by 
phosphate uptake. At all $\mathrm{pH}$ values studied, a continuous decrease in the relationship of phosphate accumulated to acid produced again was evident as the limiting accumulation was approached. The environmental $\mathrm{pH}$ dictated the point at which the phosphate accumulation and acid production became dissociated.

By contrast, with cocci maintained at $\mathrm{pH} 6.8$ during storage, the initial phosphate accumulation rates showed only slight variations in the $\mathrm{pH}$ range $7 \cdot 2$ to $5 \cdot 6$, with a mean of approximately $520 \mu$ mole/g. cocci/hr (Fig. $4 a$ ). At pH $5 \cdot \mathrm{I}$ and 4.6 these rates were about 255 and $90 \mu \mathrm{mole} / \mathrm{g}$. cocci/hr, respectively. The change in capacity for phosphate uptake was not continuous but stepwise with respect to changing $\mathrm{pH}$, the capacities being grouped as follows: $\mathrm{pH} 7 \cdot 2,7 \cdot 0$ and 6.8 exhibited the highest
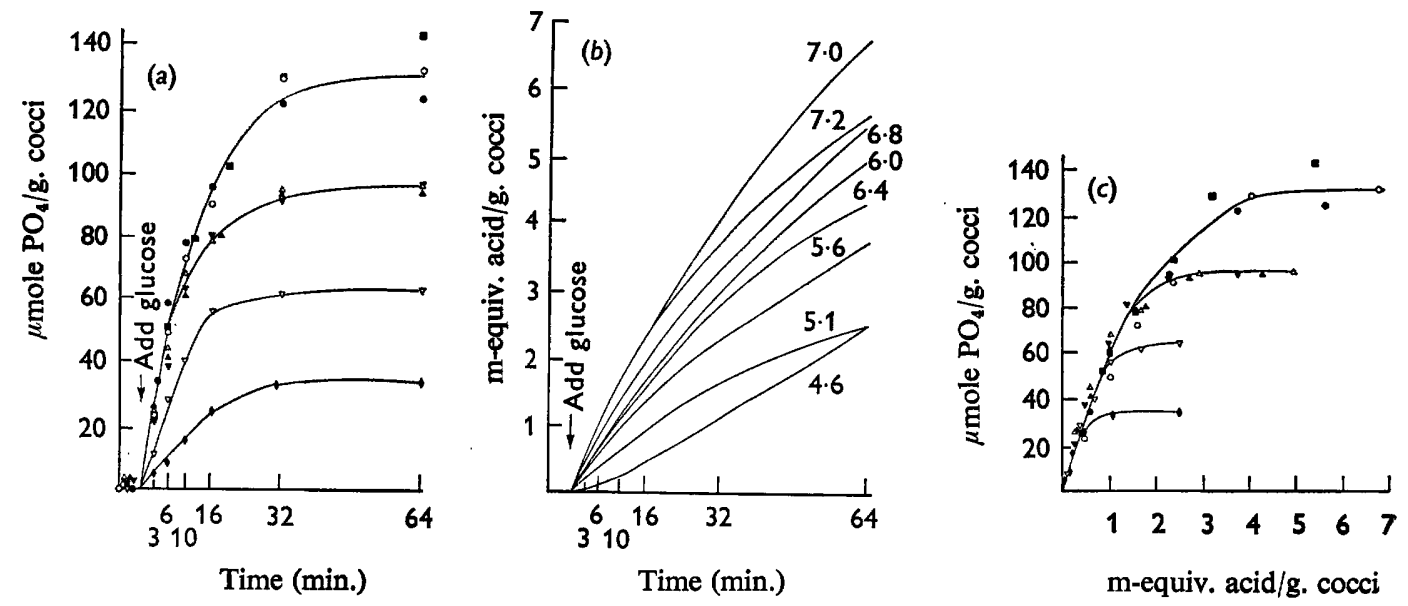

Fig. 4. Relationship of phosphate accumulation (a), acid production $(b)$, and the stoichiometric relationship of phosphate accumulation and acid production $(c)$ to the $\mathrm{pH}$ of the incubation medium. Cocci were washed and stored in $50 \mathrm{mM}-\mathrm{KCl}+\mathrm{I} \mathrm{mm}$-phosphate medium at $\mathrm{pH}$ 6.8. At the time of incubation the $\mathrm{pH}$ was adjusted to the following values: $7 \cdot 2(\bullet), 7 \cdot 0(0), 6 \cdot 8(\square), 6 \cdot 4(\Delta), 6 \cdot 0(\Delta), 5 \cdot 6(\nabla), 5 \cdot 1(\nabla)$ or $4 \cdot 6(\diamond)$. Glucose was added to the incubation medium to $0.20 \%$ after the addition of $2.25 \mu \mathrm{C} \mathrm{Na}{ }_{2} \mathrm{H}^{32} \mathrm{PO}_{4}$.

value; $\mathrm{pH} 6.4,6.0$ and 5.6 gave a discretely lower value; and $\mathrm{pH} 5 . \mathrm{I}$ and 4.6 yielded progressively lower total accumulations. Therefore, it appeared that the environmental $\mathrm{pH}$ ultimately regulated the absolute levels to which phosphate could be accumulated, but did not substantially affect the rate of that accumulation at $\mathrm{pH}$ $7 \cdot 2$ to $5 \cdot 6$. The initial rates of acid production are shown in Fig. $4 b$, they ranged from II $.0 \mathrm{~m}$-equiv./g. cocci/hr to $2.6 \mathrm{~m}$-equiv./g. cocci/hr (the maximal rate at $\mathrm{pH} 4 \cdot 6$ ). At all $\mathrm{pH}$ values studied, the stoichiometric relationship between phosphate accumulation and acid production was essentially the same until the limit of accumulation was approached for each case (Fig. $4 \mathrm{c}$ ). Again, the environmental pH dictated the point of dissociation of these events. This dissociation occurred latest at $\mathrm{pH} 7 \cdot 2,7 \cdot 0$ and 6.8; earlier at $\mathrm{pH} 6.4,6.0$ and 5.6; still earlier at $\mathrm{pH} 5 . \mathrm{I}$; and earliest at $\mathrm{pH} 4.6$.

Thus, the rates of phosphate accumulation and acid production, although variable, remain coupled, irrespective of the $\mathrm{pH}$ conditions of the storage and/or incubation.

Absence of backflux of phosphate. The specific activity (c.p.m. $/ \mu$ mole $o-\mathrm{PO}_{4}$ ) of filtrates of the suspension was evaluated during the accumulation of labelled phosphate 
to detect the possible efflux of unlabelled phosphate from cocci. The specific activity did not change detectably, since chemically analysed phosphate and radioactivity disappeared in equal proportion from the filtrate (Fig. 5). Hence, the net flux of phosphate observed in these experiments is essentially equal to influx, efflux being insignificant.

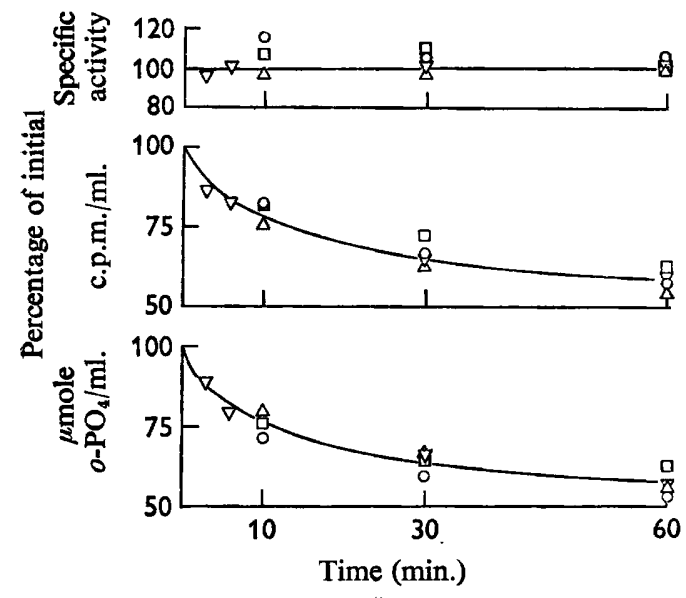

Fig. 5

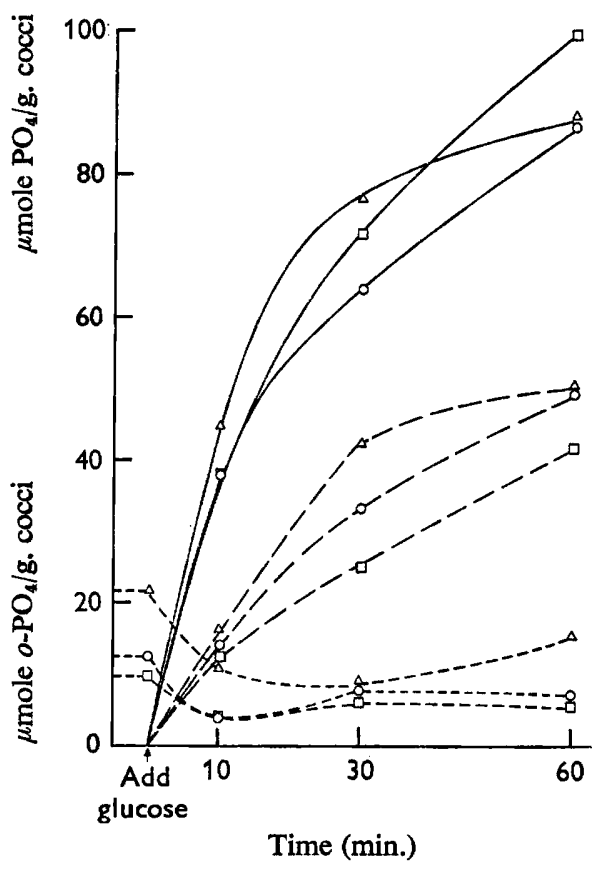

Fig. 6

Fig. 5. Change of $o-\mathrm{PO}_{4}$ concentration, radioactivity and specific activity of the filtrates of the cell suspension during incubation. Standard conditions of incubation with glucose $(0.2 \%)$ added after the addition of $2.25 \mu \mathrm{C} \mathrm{Na}{ }_{2} \mathrm{H}^{32} \mathrm{PO}_{4}$ were used. Data are expressed as $\%$ of initial values. Four experiments are represented by different symbols. $(O, \square, \triangle, \nabla)$.

Fig. 6. Accumulation of phosphate into cold $\mathrm{HClO}_{4}$-extractable and $\mathrm{H}_{2} \mathrm{SO}_{4}$-digestible fractions, and concentration of $o-\mathrm{PO}_{4}$ in the cold $\mathrm{HClO}_{4}$ extract of cocci during incubation. Standard conditions of incubation with glucose $(0.2 \%)$ added after the addition of $2.25 \mu \mathrm{C}$ $\mathrm{Na}_{2} \mathrm{H}^{32} \mathrm{PO}_{4}$ were used. Uptake of phosphate into $\mathrm{H}_{2} \mathrm{SO}_{4}$-digestible material is indicated by $(-)$, and into cold $\mathrm{HClO}_{4}$-extractable material by $(---)$. The concentration of $o-\mathrm{PO}_{4}$ in the cold $\mathrm{HClO}_{4}$-extractable fraction is indicated by (-..). The symbols denote three experiments whose corresponding values of filtrate $0-\mathrm{PO}_{4}$ concentration, radioactivity and specific activity are given by the same symbols in Fig. 5 .

General compartmental distribution of accumulated phosphate. In view of the unidirectional flux described above, uptake into the total phosphate pool was calculated by dividing the c.p.m./g. cocci of $\mathrm{H}_{2} \mathrm{SO}_{4}$ digest by the mean c.p.m./ $\mu$ mole $o-\mathrm{PO}_{4}$ of the filtrate. Uptake into the cold $\mathrm{HClO}_{4}$ extractable pool was computed similarly. Figure 6 shows that approximately half of the accumulated phosphate was not extracted by cold$\mathrm{HClO}_{4}$ and presumably represents high molecular weight material. Chemical analysis of $o-\mathrm{PO}_{4}$ in the cold $\mathrm{HClO}_{4}$-extractable material showed initial values of 9.5 to $22 \cdot 2 \mu$ mole/g. cocci. This pool contracted by over $50 \%$ after the addition of glucose and then tended to return to the original levels. 
Comparison of the cold $\mathrm{HClO}_{4}$-extractable $o-\mathrm{PO}_{4} / \mathrm{g}$. cocci with $o-\mathrm{PO}_{4} / \mathrm{ml}$. of culture filtrate indicates that cellular $o-\mathrm{PO}_{4}$ is 5.0 to 35 times more concentrated than medium $o-\mathrm{PO}_{4}$ (these data are not corrected for the non-aqueous mass of the cocci). In other experiments with an initial concentration of $0.2 \mathrm{mM}-o-\mathrm{PO}_{4}$ in the medium, $83 \%$ of extracellular radioactivity was accumulated by the cocci in $64 \mathrm{~min}$. Assuming intracellular $o-\mathrm{PO}_{4}$ concentrations to be similar to those observed in the present experiment, one would expect cocci/medium $o-\mathrm{PO}_{4}$ ratios in that experiment to be on the order of 25 to 130 . Hence, $o-\mathrm{PO}_{4}<$ must move into the cocci against a chemical gradient even though the intracellular $o-\mathrm{PO}_{4}$ pool is continously being depleted.

\section{DISCUSSION}

The accumulation of phosphate by SL-I was strictly energy-dependent, essentially unidirectional and coupled stoichiometrically to acid production. Energy-dependent and unidirectional phosphate flux has been described for yeast (Hevesy, LinderstromLang \& Nielsen, I937; Goodman \& Rothstein, 1957; Leggett, 196I; Borst Pauwels, 1962) and Streptococcus faecalis (Harold, Harold \& Abrams, 1965). The stoichiometric relationship between phosphate accumulation and acid production demonstrates a coupling which has not been described by other authors.

Coupling occurred over wide ranges of extracellular glucose concentration, extracellular phosphate concentration, and extracellular $\mathrm{pH}$. A point of uncoupling is, however, dictated by the environmental $\mathrm{pH}$. Acid production continued longer than phosphate uptake, which appeared to have a capacity limited by extracellular $\mathrm{pH}$. Phosphate accumulation did not occur in the absence of acid production; however, acid production occurred in the absence of added phosphate. The data do not indicate the closeness of the coupling nor the direct energetic cost of phosphate accumulation.

The rate of phosphate uptake was independent of the environmental glucose concentration in the range 0.01 to $0.30 \%(\mathrm{w} / \mathrm{v})$. These glucose concentrations were presumably saturating and submaximal rates of phosphate accumulation would be observed at lower glucose concentrations. The rate of phosphate accumulation showed saturation kinetics with respect to the environmental concentration of phosphate.

The rate of accumulation of phosphate by SL-I was essentially independent of $\mathrm{pH}$ from $7 \cdot 2-5 \cdot 6$ provided that the cocci studied had been harvested and stored at $\mathrm{pH} 6 \cdot 8$. This is similar to the behaviour of Streptococcus faecalis as shown by Harold et al. (1965), who harvested cells in salts-maleate buffer at $\mathrm{pH} 7.0$ and tested phosphate accumulation immediately. By contrast, when SL-I cocci were harvested and stored at the $\mathrm{pH}$ values to be tested, phosphate accumulation rates were strongly $\mathrm{pH}$ dependent. This finding is similar to those observed with Staphylococcus aureus (Mitchell, 1954) and yeast (Goodman \& Rothstein, 1957). These observed variations of phosphate uptake rate with extracellular $\mathrm{pH}$, at least with SL-I, may be due to disruption of the phosphate accumulative machinery incurred when energy-depleted cocci are faced with disadvantageous environmental $\mathrm{pH}$ for a prolonged period of storage. The hypothesis of Goodman \& Rothstein (1957) that $\mathrm{H}_{2} \mathrm{PO}_{4}{ }^{-}$is transported in preference to $\mathrm{HPO}_{4}{ }^{2-}$ by yeast seems inadequate to explain the experimental observations of the $\mathrm{pH}$ dependency of phosphate accumulation rate with SL-I and S. faecalis (Harold et al. 1965).

The effect of the environmental $\mathrm{pH}$ on the rate of glycolysis is not clear from the literature. Some reports show that fermentation rates are essentially independent of 
$\mathrm{pH}$ over a wide range. Below $\mathrm{pH} 5 \cdot 0$ the rate of yeast fermentation depends upon the amount of $\mathrm{K}^{+}$present in the incubation medium, $\mathrm{K}^{+}$counteracting the depressant effect of $\mathrm{H}^{+}$on fermentation (Rothstein, I954). Stralfors (1950), however, showed with a number of isolates of streptococci, staphylococci, lactobacilli, Gaffkya, Neisseria and yeast that the rate of acid production from glucose depends upon the extracellular $\mathrm{pH}$. No clear difference was apparent with the presence or absence of $10 \mathrm{mM}-$ $\mathrm{K}^{+}$in the incubation fluid. The rate of acid production by SL-I was dependent upon extracellular $\mathrm{pH}$, even in the presence of $50 \mathrm{~mm}-\mathrm{K}^{+}$in the medium. The effect of $\mathrm{pH}$ is probably not due to variation in the products of glucose fermentation since lactate is the predominant end product at pH 7.0 or below (Gunsalus \& Niven, 1942; Platt \& Foster, 1958). In view of the coupling of phosphate accumulation to acid production, the $\mathrm{pH}$ effect upon the regulation of the rate of glycolysis probably directly regulates the energy supply which in turn determines the rate of phosphate accumulation.

By contrast with the rate of phosphate accumulation, the capacity for phosphate accumulation appeared to be controlled by the extracellular $\mathrm{pH}$ regardless of the storage conditions. It is not clear how this effect is mediated, but it cannot be ascribed to a limitation of energy since glycolysis continued unabated long after phosphate accumulation terminated.

These experiments showed that the concentration of $o-\mathrm{PO}_{4}$ in the intracellular pool was always greater than the extracellular concentration. They also showed that during phosphate uptake the intracellular $o-\mathrm{PO}_{4}$ pool contracted by more than $50 \%$. If one assumes that $0-\mathrm{PO}_{4}$ taken up from the extracellular fluid passes through the intracellular $o-\mathrm{PO}_{4}$ compartment, then the incorporation of $o-\mathrm{PO}_{4}$ into other phosphatecontaining constituents must be more rapid than the transport of $o-\mathrm{PO}_{4}$ into the coccus. On the other hand, if extracellular $o-\mathrm{PO}_{4}$ does not initially mix with the intracellular $o-\mathrm{PO}_{4}$ pool, it is still clear that the synthetic events attendent to phosphate accumulation take place partially at the expense of the intracellular o- $\mathrm{PO}_{4}$ compartment. The suggestion has been made with other cell systems that $o-\mathrm{PO}_{4}$ incorporated from extracellular fluid does not immediately pass through the intracellular $o-\mathrm{PO}_{4}$ pool (Ginsburg, 1967; Vestergaard-Bogind, I963).

Since approximately $50 \%$ of the phosphate accumulated by SL-I was not extractable with cold $\mathrm{HClO}_{4}$, it would appear that a considerable synthesis of high molecular weight material occurs. Furthermore, since the pool of $o-\mathrm{PO}_{4}$ contracted during the accumulation process, a large portion of the cold $\mathrm{HClO}_{4}$-extractable accumulated phosphate must also represent synthetic products.

Phosphate accumulated into the high molecular weight material probably is not located in de novo synthesized pools of DNA, RNA, protein or cell-wall constituents. Two lines of reasoning lead to this conclusion. Firstly, cocci depleted of an exogenous nitrogen source are not capable of significant growth or net synthesis of DNA, RNA and protein. The absence of an increase of DNA in the experimental incubation system supported this assumption. Secondly, unpublished studies of the metabolic fate of glucose-U $-{ }^{14} \mathrm{C}$ indicated complete recovery of glucose carbon in either residual sugar, carboxylic acids, small amounts of Embden-Meyerhof intermediates, or $\mathrm{CO}_{2}$. Thus, no carbon is available for appreciable synthesis of nucleic acids, proteins or cell wall constituents. However, exchange of ${ }^{32} \mathrm{P}$ for ${ }^{31} \mathrm{P}$ in these pools is not ruled out. The presence of polyphosphate has not been described in streptococci (Harold, 1966). Although no direct evidence is now available, the data presented here are consistent 
with the hypothesis that a large portion of the accumulated phosphate is polymerized as an inorganic polyphosphate.

The authors wish to express their thanks to Dr Estelle R. Ramey, Department of Physiology and Biophysics, Schools of Medicine and Dentistry, Georgetown University, Washington, D.C., for helpful discussions during the course of this work.

\section{REFERENCES}

Borst Pauwels, G. S. F. H. (1962). The uptake of radioactive phosphate by yeast. I. The uptake of phosphate by yeast compared with that by higher plants. Biochim. biophys. Acta 65, 403 .

BuRnHAM, J. C. \& HAGEAGE, G. J., JUN. (1967). Adenosine phosphate hydrolases in fractions of Vitreosilla. J. Bact. 93, 191.

Burton, K. (1956). A study of the conditions and mechanism of the diphenylamine reaction for the colorimetric estimation of deoxyribonucleic acid. Biochem. J. 62, 315.

FitzGeraid, R. J. \& KeYES, P. H. (1960). Demonstration of the etiologic role of streptococci in experimental caries in the hamster. J. Am. dent. Ass. 6r, 9.

GinsBuRG, J. M. (I967). Renal tubular transport of phosphate and ${ }^{\text {32P }}$ exchange in the dog. Physiologist 10, 181.

Goodman, J. \& Rothstein, A. (1957). The active transport of phosphate into the yeast cell. J. gen. Physiol. 40, 915.

Gordan, C. F. \& Wolfe, A. L. (1960). Liquid scintillation counting of aqueous samples. Analyt. Chem. 32, 574.

Gunsalus, I. C. \& NIVEN, C. F., Jun. (1942). The effect of pH on the lactic acid fermentation. J. biol. Chem. I45, I3I.

HAROLD, F. M. (1966). Inorganic polyphosphates in biology: structure, metabolism and function. Bact. Rev. 30, 772.

Harold, F. M., Harold, R. L. \& Abrams, A. (1965). A mutant of Streptococcus faecalis defective in phosphate uptake. J. biol. Chem. 240, 3145.

Hevesy, G., Linderstrom-LANG, K., \& NieLSEN, N. (1937). Phosphorous exchange in yeast. Nature, Lond. 140, 725.

JORDAN, H. V., FITZGERALD, R. J. \& BowleR, A. E. (I960). Inhibition of experimental caries by sodium metabisulfite and its effect on the growth and metabolism of selected bacteria. J. dent. Res. 39, I16.

KINARD, F.E. (1957). Liquid scintillator for the analysis of tritium in water. Rev. scient. Instrum. 28, 293.

LEGGETT, J. E. (1961). Entry of phosphate into yeast cell. Pl. Physiol. 36, 277.

Luoma, H. (1964). Lability of inorganic phosphate in dental plaque and saliva. Acta odont. scand. 22 (Suppl. 4I), 7.

MARTONOSI, A. (1960). Chromatographic separation of phosphate compounds. Biochem. biophys. Res. Comm. 2, 12.

Mrtchell, P. (1954). Transport of phosphate across the osmotic barrier of Micrococcus pyogenes. Specificity and kinetics. J. gen. Microbiol. II, 73.

OguR, M. \& Rosen, G. (1950). The nucleic acids of plant tissues. I. The extraction and estimation of desoxypentose nucleic acid and pentose nucleic acid. Archs. Biochem. 25, 262.

Platt, T. B. \& Foster, E. M. (1958). Products of glucose metabolism by homofermentative streptococci under anaerobic conditions. J. Bact. 75, 453.

PotreR, V. R. (1947). The assay of animal tissues for respiratory enzymes. J. biol. Chem. 169, 17.

RothsTEIN, A. (1954). Enzyme systems of the cell surface involved in the uptake of sugars by yeast. Symp. soc. exp. Biol. 8, 166.

Stralfors, A. (1950). The bacterial chemistry of dental plaques. Odont. Tidskr. 58, I55.

UMBREIT, W. W., BurRIs, R. H. \& STAUfFER, J. F. (I957). Methods for the analysis of phosphorylated intermediates. In Manometric Techniques, chap. 16, p. 268. Minneapolis: Burgess Publishing.

VESTERGAARD-BOGIND, B. (1963). The transport of phosphate ions across the human red cell membrane. II. The influence of the concentration of inorganic phosphate on the kinetics of the uptake of $\left({ }^{32} \mathrm{P}\right)$ phosphate ions. Biochim. biophys. Acta 66, 93. 